\title{
Effects of Dry-Land Strength and Conditioning Programs in Age Group Swimmers
}

\author{
Nuno M. Amaro,,${ }^{1,2}$ Daniel A. Marinho, $, 2,3$ Mário C. Marques, ${ }^{2,3}$ Nuno P. Batalha, ${ }^{2,4}$ and \\ Pedro G. Morouço ${ }^{5}$ \\ ${ }^{1}$ Life Quality Research Center, Polytechnic Institute of Leiria, Leiria, Portugal; ${ }^{2}$ Research Center in Sports, Health and Human \\ Development, CIDESD, Vila Real, Portugal; ${ }^{3}$ Department of Sport Sciences, University of Beira Interior, Covilha, Portugal; \\ ${ }^{4}$ Departament of Sport and Health, School of Science and Technology, University of Évora, Évora, Portugal; and ${ }^{5}$ Center for \\ Rapid and Sustainable Product Development, Polytechnic Institute of Leiria, Marinha Grande, Portugal
}

\begin{abstract}
Amaro, NM, Marinho, DA, Marques, MC, Batalha, N, and Morouço, PG. Effects of dry-land strength and conditioning programs in age group swimmers. J Strength Cond Res 31(9): 2447-2454, 2017 -Even though dry-land S\&C training is a common practice in the context of swimming, there are countless uncertainties over its effects in performance of age group swimmers. The objective was to investigate the effects of dry-land S\&C programs in swimming performance of age group swimmers. A total of 21 male competitive swimmers ( $12.7 \pm 0.7$ years) were randomly assigned to the Control group $(n=7)$ and experimental groups GR1 and GR2 ( $n=7$ for each group). Control group performed a 10-week training period of swim training alone, GR1 followed a 6-week dryland S\&C program based on sets and repetitions plus a 4-week swim training program alone and GR2 followed a 6-week dry-land S\&C program focused on explosiveness, plus a 4-week program of swim training alone. Results for the dry-land tests showed a time effect between week 0 and week 6 for vertical jump $(p<0.01)$ in both experimental groups, and for the GR2 ball throwing ( $p<$ 0.01 ), with moderate to strong effect sizes. The time $\times$ group analyses showed that for performance in $50 \mathrm{~m}$, differences were significant, with the GR2 presenting higher improvements than their counterparts $\left(F=4.156 ; p=0.007 ; \eta_{p}^{2}=0.316\right)$ at week 10. Concluding, the results suggest that 6 weeks of a complementary dry-land S\&C training may lead to improvements in dry-land strength. Furthermore, a 4-week adaptation period was mandatory to achieve beneficial transfer for aquatic performance. Additional benefits may occur if coaches plan the dry-land S\&C training focusing on explosiveness.
\end{abstract}

KEY WoRDS swimming, exercise testing, sprint performance, explosiveness

Address correspondence to Pedro G. Morouço, pedro.morouco@ipleiria.pt.

31(9)/2447-2454

Journal of Strength and Conditioning Research

(C) 2016 National Strength and Conditioning Association

\section{INTRODUCTION}

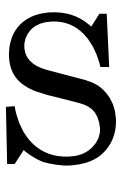
trength and conditioning $(\mathrm{S} \& \mathrm{C})$ training is a common practice in most sports, aiming to enhance performance and prevent injuries $(3,7,8,15)$. Yet, the $\mathrm{S} \& \mathrm{C}$ training design should be specific for the requirements of the concerned sport. In swimming, performance is highly dependent on strength and muscular power $(5,11,14,21)$, being the ability to exert force in the water a decisive factor, specifically in short distances $(18,25)$. Consequently, swimming coaches traditionally apply dry-land $\mathrm{S} \& \mathrm{C}$ programs in their training sessions $(1,3,9,23)$ even if consensus on the specific benefits to a swimmer's performance has not yet been clarified in literature $(11,23,27,33)$. It is suggested that transferability of dry-land strength gains to swimming performance depends on the interaction of several parameters such as strength (dry-land and in-water) and biomechanics (kinematics and kinetic) (2). On this, there are many coaches who assume that strength training could negatively affect a swimmer's ability and, consequently, increase drag forces (21). This is mostly due to the muscular hypertrophy and flexibility decrease, commonly identified as outputs of strength training. Nevertheless, during the prepubescent stage, muscle hypertrophy is not believed to be the primary factor in strength improvement (28), as neuromuscular adaptations are identified as the main explanations for strength gains $(7,8)$. Unfortunately, the number of investigations able to clarify this subject is scarce, most likely due to financial and ethical issues, particularly if we look for research with age group swimmers (4).

Apart from the above-mentioned need of clarification, it is suggested by deterministic models (2) that muscular strength may influence technique and, therefore, performance. Additionally, if it is considered that swimming techniques can be improved due to dry-land $\mathrm{S} \& \mathrm{C}$ training (17) and that it is common to apply dry-land $\mathrm{S} \& \mathrm{C}$ training programs to swimming, understanding the effects that the dry-land $\mathrm{S} \& \mathrm{C}$ training programs may induce is mandatory. On one hand, several investigations have shown improvements in swimming performance $(1,10,11,26)$ after a dry-land $\mathrm{S} \& \mathrm{C}$ training program intervention. For instance, a recent investigation (10) presented an increase of $2.0 \pm 1.3 \%$ in the $50 \mathrm{~m}$ freestyle 
performance after the application of a dry-land $\mathrm{S} \& \mathrm{C}$ program for 4 weeks ( 3 sessions per week, of 15 minutes each) with an intensity between 80 and $90 \%$ of one repetition maximum (1RM). On the other hand, other investigations stated that a dry-land S\&C program intervention promotes strength gains, but that these gains have no significant direct transfer for swimming performance improvements $(9,23,27,33)$. The reasons for these differences may be different protocol interventions or design, time-period applications, and sample size. For instance, some studies pooled together both genders in one single group. Despite the fact that during preadolescence, strength improvements are quite similar between boys and girls (8), after this period, boys have a tendency to exhibit higher muscle strength levels than girls (6). Thus, coupling data from both genders in research focused on dry-land $\mathrm{S} \& \mathrm{C}$ may be misleading. Furthermore, even if no statistically significant improvements were stated, recent investigations with young swimmers found a tendency to improve sprint performance in the 25 and $50 \mathrm{~m}$ freestyle, due to dry-land $\mathrm{S} \& \mathrm{C}$ programs $(9,23)$. These investigations, whether with significant results or only with a tendency to enhance performance, have a common point: short swimming distances. So, the ability to exert high levels of force for a short period of time seems relevant for an appropriate training prescription and demands further investigations.

It is well stated in the literature that movements performed when swimming are difficult to replicate on dry-land, as water drag is impossible to reproduce in dryland exercises $(17,23,27,31)$. Therefore, a dry-land $\mathrm{S} \& \mathrm{C}$ program design should try to mimic the in-water movements as much as possible. Perhaps some of the previous investigations, which did not accomplish improvements in swimming performance, could have used exercises with low mimicking or did not use as much muscular tension as in the water (3). Another decisive factor could be the minor importance to overall swimming performance of the muscles worked out in dry-land $\mathrm{S} \& \mathrm{C}$ programs (5). Moreover, the velocity with which exercises were performed could have been different from the in-water performance $(3,16,17,27,30)$. Several studies followed a 1RM methodology to define the exercises' external load. Nevertheless, it is questionable whether maximum force is the force parameter with a higher association with swimming performance, as swimming power has proven to be of major importance in shorter distances $(5,18,25,29)$. Thus, it may be expected that movement velocity plays an important role in increasing the specificity of dry-land S\&C exercises (12) and overall power output. Still, the strength programs analyzed are not explicit about the exercise movement velocity.

One last point regarding dry-land $\mathrm{S} \& \mathrm{C}$ programs for swimming is related to the moments when evaluations are carried out after the dry-land $\mathrm{S} \& \mathrm{C}$ program interventions. Commonly, research is interested in knowing the effects of a designed intervention, thus, making evaluations before and after the application period. However, it has been hypothesized that swimmers could benefit from an adaptation period to the strength gains (17). That is, after increasing strength levels, swimmers should go through a period to adapt their ability to apply new levels of force in the water. To the best of our knowledge, only 2 studies have investigated detraining or delayed effects after dry-land $\mathrm{S} \& \mathrm{C}$ programs interventions $(9,10)$. Both investigations reported that training effects were maintained after 6 and 4 weeks, respectively. So, it seems reasonable to investigate whether a period where swimmers could perform this specific in-water training would be useful to effective take advantage of dry-land $\mathrm{S} \& \mathrm{C}$ programs improvements (9).

The above-mentioned uncertainties regarding the benefits of dry-land $\mathrm{S} \& \mathrm{C}$ training programs and their effect on swimming performance highlight the need for more investigations on this matter. In fact, being able to clarify the role of dryland $S \& C$ training and its prescription would be of major value for swimming coaches. Therefore, this study aimed to analyze the effects of a period of swim training alone, a dryland $\mathrm{S} \& \mathrm{C}$ program based on sets and repetitions according to current guidelines, plus swim training alone or a dry-land $\mathrm{S} \& \mathrm{C}$ program that focused on explosiveness plus swim training alone, in age group swimmers. It was hypothesized that (a) a dry-land $\mathrm{S} \& \mathrm{C}$ training program would be able to enhance both dry-land strength and swimming performance, if adaptation for strength gain occurs and (b) that a dry-land $\mathrm{S} \& \mathrm{C}$ program focused on explosiveness development would be more suitable to increasing swimming performance in short distance events.

\section{MeThods}

\section{Experimental Approach to the Problem}

A randomized controlled trial, with balance randomization, parallel group was conducted at the competitive period of the spring training, ensuring that the subjects were in a prime training period cycle and was performed in an on-field setting. Twenty-one participants were randomly assigned into 2 experimental groups and 1 control group according to the random number table ( $n=7$ for each group).

\section{Subjects}

Twenty-one male prepubescent swimmers $(2.1 \pm 0.4$ Tanner stages by self-evaluation) were recruited by convenient sampling to take part in the study, as observed in Table 1 . Eligible participants were age-group swimmers of teams competing in the first national division (Portugal). Inclusion criteria required that swimmers had at least 2 years of experience in swimming competition. Participants were excluded if they had an injury or had regularly participated in any kind of strength training before this investigation. Swimmers were randomly assigned using computerized randomization and allocated into 3 groups (GR1, GR2, and CG) based on similar swimming performance (1:1:1). None of the groups was aware of the existence of other groups in the experiment. 
TABLE 1. Main physical characteristics of the subjects, according to the group.

\begin{tabular}{lccc}
\hline & Age $(\mathrm{y})$ & Height $(\mathrm{m})$ & Body mass $(\mathrm{kg})$ \\
\hline Group 1 $(n=7)$ & $12.7 \pm 0.8$ & $1.57 \pm 0.07$ & $47.9 \pm 7.2$ \\
Group 2 $(n=7)$ & $12.7 \pm 0.8$ & $1.58 \pm 0.09$ & $47.4 \pm 10.0$ \\
Control group $(n=7)$ & $12.6 \pm 0.8$ & $1.55 \pm 0.07$ & $47.8 \pm 12.8$ \\
\hline
\end{tabular}

each session. The goal was to elevate body temperature and enhance motor unit excitability. Rope skipping and similar articular mobilization to $\mathrm{S} \& \mathrm{C}$ exercises were used (8). The program consisted of 5 different exercises: medicine ball throw down; countermovement jump; dumbbell flys; Russian twist; and push-ups. For the medicine ball throw down, participants started in an upright position with the ball

Since the sample size comprises a low number of subjects, statistical analyses were performed to assess the sample's power. The results showed an effect size of $0.3, \alpha=0.05$, and $\beta=0.7$. All groups had 5.8 training sessions per week with an average of $4.075 \pm 0.2 \mathrm{~km}$ per training unit. The study was conducted in accordance with the ethics committee of the host institution and with the Declaration of Helsinki for research involving human participants. All parents gave their written informed consent and under-age subjects their assent.

\section{Procedures}

The experimental period for the present study was 10 weeks, divided into 2 periods: the dry-land $\mathrm{S} \& \mathrm{C}$ implementation period (6 weeks) and an adaptation period ( 4 weeks). Previous investigations using subjects with similar age were conducted through 8 weeks (9). Additionally, and to fit in one available planning meso-cycle, the duration of 6 weeks (2 meso-cycles of 3 weeks each) of dry-land S\&C training intervention was chosen.

Dry-land S\&C training sessions (2 sessions per week of 30 minutes each, before in-water training) took part in addition to regular swimming training sessions. Table 2 presents a detailed description of the dry-land $S \& C$ training program. Sessions were conducted by $2 \mathrm{~S} \& \mathrm{C}$ coaches, always with the presence of the head coach. $\mathrm{S} \& \mathrm{C}$ training was planned and supervised by an NSCA Certified Strength and Conditioning Specialist. Preceding the dry-land S\&C training exercises, a warm-up of approximately 10 minutes was completed in
(1 kg) above the head, with upper limbs fully extended and threw it to the ground, as fast as they could. The countermovement jump was made to a higher surface (box) with $30 \mathrm{~cm}$ height. Dumbbell flys were performed with participants lying on the ground. The exercise started with upper limbs in a vertical position where dumbbells weighing $1.5 \mathrm{~kg}$ had to reach the minimum distance to the ground, without contact on it. Upper limbs were fully extended during the exercise. Russian twists were performed with a medicine ball that weighed $3 \mathrm{~kg}$. Participants started in a seated position with arms fully extended in the front of their chest and with feet off the ground. The ball had to be displaced from the right hip to the left hip, with precision. Push-ups were performed with upper limbs in adduction, close to upper body during the duration of exercise. The body had to remain in plank during the exercise. Strength training followed 2 different dry-land S\&C programs as shown in Table 2.

Experimental GR1 performed exercises following a sets and repetitions methodology with no restrictions on the time of execution (Table 2). A rest period between sets was incremented every 2 weeks of intervention (40 seconds, 60 seconds, and $1 \mathrm{~m} 30$ seconds). This methodology is similar to previous studies (9) and is traditionally used in $\mathrm{S} \& \mathrm{C}$ training programs (8). Instead, experimental GR2 followed an explosiveness methodology, where subjects had to perform as many repetitions as they could in a specific time (Table 2). Swimmers were told to perform the repetitions as rapidly as possible. A rest period between sets was always calculated by

TABLE 2. Strength and conditioning training programs, according to group.

\begin{tabular}{|c|c|c|c|c|c|c|}
\hline & \multicolumn{3}{|c|}{ Group 1} & \multicolumn{3}{|c|}{ Group 2} \\
\hline & Week 1-2 & Week 3-4 & Week 5-6 & Week 1-2 & Week 3-4 & Week 5-6 \\
\hline Medicine ball throw down $1 \mathrm{~kg}$ & $3 \times 8$ & $3 \times 12$ & $3 \times 15$ & $3 \times 15 s$ & $3 \times 20 \mathrm{~s}$ & $3 \times 25 s$ \\
\hline $\mathrm{CMJ}$ to box $30 \mathrm{~cm}$ & $3 \times 10$ & $3 \times 14$ & $3 \times 18$ & $3 \times 15 s$ & $3 \times 20 s$ & $3 \times 25 s$ \\
\hline Dumbbell Flys $1.5 \mathrm{~kg}$ & $3 \times 6$ & $3 \times 10$ & $3 \times 15$ & $3 \times 10 \mathrm{~s}$ & $3 \times 15 s$ & $3 \times 20 s$ \\
\hline Russian twist $3 \mathrm{~kg}$ & $3 \times 10$ & $3 \times 14$ & $3 \times 18$ & $3 \times 15 s$ & $3 \times 20 \mathrm{~s}$ & $3 \times 25 s$ \\
\hline Push-ups & $3 \times 10$ & $3 \times 14$ & $3 \times 18$ & $3 \times 10 \mathrm{~s}$ & $3 \times 15 \mathrm{~s}$ & $3 \times 20 \mathrm{~s}$ \\
\hline
\end{tabular}


TABLE 3. Mean force, mean mechanical impulse, vertical jump, and ball throwing mean values $( \pm S D)$, differences $(\%)$, significance $(p)$, and effect sizes $\left(\eta_{p}^{2}\right)$ throughout the experimental period.

\begin{tabular}{|c|c|c|c|c|c|c|c|}
\hline & T1 & $\mathrm{T} 2$ & T3 & $\begin{array}{c}\text { T1-T2 } \\
\text { (\%) }\end{array}$ & $\begin{array}{c}\text { T2-T3 } \\
\text { (\%) }\end{array}$ & $p$ & $\eta_{p}^{2}$ \\
\hline \multicolumn{8}{|c|}{ Mean force $(\mathrm{N})$} \\
\hline GR1 & $59.86 \pm 9.74$ & $58.57 \pm 11.26$ & $60.97 \pm 9.73$ & -2.2 & +4.09 & 0.150 & 0.271 \\
\hline GR2 & $63.82 \pm 17.20$ & $64.12 \pm 17.92$ & $66.36 \pm 17.32$ & +0.47 & +3.5 & 0.126 & 0.292 \\
\hline $\mathrm{CG}$ & $55.79 \pm 15.80$ & $56.93 \pm 16.68$ & $57.13 \pm 16.87$ & +2.04 & +0.035 & 0.335 & 0.167 \\
\hline \multicolumn{8}{|c|}{$\begin{array}{l}\text { Mean mechanical impulse } \\
\left(\mathrm{N} \cdot \mathrm{s}^{-1}\right)\end{array}$} \\
\hline GR1 & $71.49 \pm 15.51$ & $70.06 \pm 14.32$ & $72.97 \pm 20.88$ & -2.04 & +4.15 & 0.469 & 0.119 \\
\hline GR2 & $71.51 \pm 23.62$ & $73.95 \pm 26.97$ & $77.52 \pm 25.81$ & +3.41 & +4.82 & 0.255 & 0.204 \\
\hline CG & $68.72 \pm 24.08$ & $69.26 \pm 20.93$ & $68.73 \pm 20.87$ & +0.78 & -0.77 & 0.921 & 0.014 \\
\hline \multicolumn{8}{|c|}{ Vertical jump (cm) } \\
\hline GR1 & $25.70 \pm 3.29$ & $29.28 \pm 3.06^{\star}$ & $29.18 \pm 4.70$ & +13.92 & -0.34 & 0.003 & 0.617 \\
\hline GR2 & $29.70 \pm 4.73$ & $31.85 \pm 4.78^{\star}$ & $31.91 \pm 5.51$ & +7.44 & +0.18 & 0.018 & 0.487 \\
\hline CG & $25.44 \pm 4.47$ & $27.32 \pm 6.94$ & $26.88 \pm 5.48$ & +7.38 & -1.63 & 0.377 & 0.150 \\
\hline \multicolumn{8}{|c|}{ Ball throwing $(\mathrm{m})$} \\
\hline GR1 & $4.53 \pm 0.61$ & $4.81 \pm 0.59$ & $4.87 \pm 0.42$ & +6.18 & +1.24 & 0.051 & 0.391 \\
\hline GR2 & $4.07 \pm 0.54$ & $4.78 \pm 0.49^{\star}$ & $5.18 \pm 0.77$ & +17.44 & +8.36 & 0.000 & 0.856 \\
\hline $\mathrm{CG}$ & $3.98 \pm 0.89$ & $4.25 \pm 0.78$ & $4.40 \pm 0.86$ & +6.78 & +3.52 & 0.056 & 0.481 \\
\hline
\end{tabular}

*Significantly different from T1 $(p<0.01)$.

the multiplication of the execution time by 4 . This methodology was chosen to allow each participant to perform as many repetitions as possible. The time of each set tried to approach the time spent in short distances swimming. This way, and controlling fatigue, participants performed a similar number of actions as in swimming, attempting to be more specific for swimmers. In addition to technical follow-up, posters with images and execution criteria were printed and fixed in the gym. The quality of movement and fatigue were the 2 main aspects controlled by coaches.

Finally, the $\mathrm{CG}$ followed the regular swimming training. During the 10 weeks of the experimental period, subjects performed 58 swimming training sessions (5.8 per week). The participants swam $236.4 \mathrm{~km}$, the equivalent to a mean value of $23.64 \pm 2.4 \mathrm{~km} \cdot \mathrm{wk}$ and $4.08 \pm 0.21 \mathrm{~km}$ per training unit. A volume of $23.7 \mathrm{~km}$ was performed at an intensity equivalent to their critical velocity $(2.37 \pm 0.85 \mathrm{~km} \cdot \mathrm{wk})$ and $13.3 \mathrm{~km}$ at an intensity equivalent to their aerobic power $(1.33 \pm 1.16 \mathrm{~km} \cdot$ week). The remaining training program contained low aerobic $(\sim 70 \%$ of total volume), technical $(\sim 14 \%)$, and velocity $(\sim 1 \%)$ sets. Throughout the 4 weeks after the implementation of the $\mathrm{S} \& \mathrm{C}$ programs, sets focused on velocity increase to $\sim 2 \%$.

\section{Assessment}

Test procedures occurred at 3 different moments: (a) before the experimental procedure-pretest, (b) after 6 weeks of a strength training program-midtest, and (c) 4 weeks after the end of the strength training program-posttest. Test procedures took place at 3 different moments: at baseline; immediately after the end of the 6 weeks of the dry-land $\mathrm{S} \& \mathrm{C}$ program; and 4 weeks after the end of the dry-land $\mathrm{S} \& \mathrm{C}$ program. Tests were performed at the same time of the day to avoid any effect of circadian rhythms. The 2

TABle 4. Front crawl swimming performance mean values $( \pm S D)$, differences $(\%)$, significance $(p)$ and effect sizes $\left(\eta_{p}^{2}\right)$ throughout the experimental period.

\begin{tabular}{lccccccc}
\hline Swimming performance $(\mathrm{s})$ & $\mathrm{T} 1$ & $\mathrm{~T} 2$ & $\mathrm{~T} 3$ & $\mathrm{~T} 1-\mathrm{T} 2(\%)$ & $\mathrm{T} 2-\mathrm{T} 3(\%)$ & $p$ & $\eta_{p}^{2}$ \\
\hline GR1 & $33.92 \pm 1.47$ & $34.52 \pm 1.52$ & $34.02 \pm 1.61$ & +1.76 & -1.46 & 0.315 & 0.175 \\
GR2 & $33.43 \pm 2.83$ & $32.35 \pm 2.36$ & $31.65 \pm 2.53^{*}$ & -3.33 & -2.21 & 0.003 & 0.616 \\
GG & $33.76 \pm 3.14$ & $33.63 \pm 3.71$ & $33.64 \pm 3.04$ & -0.38 & +0.02 & 0.925 & 0.156 \\
\hline
\end{tabular}

*Significantly different from T2 $(p=0.03)$. 
experimental groups and the $\mathrm{CG}$ were evaluated at the same moment in the procedures schedule. The evaluations were conducted for 3 days for each moment. All subjects were informed of and familiarized with all test procedures 4 weeks before the first evaluation.

A maximal intensity front crawl tethered swimming was conducted to measure force produced in water, as previously described (19). After an $800 \mathrm{~m}$ moderate intensity warm-up (300 m swim, $50 \mathrm{~m}$ pull, $50 \mathrm{~m}$ kick, $4 \times 50 \mathrm{~m}$ at increasing speed, $200 \mathrm{~m}$ easy swim) each participant performed the test. Before the starting signal, participants assumed a horizontal position with the cable fully extended. Data collection began after the first stroke cycle was completed. This procedure was used to avoid the inertial effect of the cable extension usually created immediately before or during the first arm action (18). The duration of the exercise was 40 seconds with an initial phase of 10 seconds with moderate intensity and 30 seconds with maximum intensity. Participants were asked to use the breathing pattern they would normally apply during a $50 \mathrm{~m}$ front crawl event. They were also verbally encouraged throughout the test to maintain maximal effort. An acoustic signal marked the end of the test. Values of mean force as the mean of force values recorded during the 30 seconds, and mechanical impulse as the mean impulse determined as the quotient of the sum of the single-stroke impulse, and the number of strokes performed during the 30second tethered swim were estimated.

Dry-land strength tests were performed after a standard warm-up of articular mobilization and rope skipping of approximately 10 minutes. Ball thrown distance (in meter) was measured through a maximal throwing velocity test using a $1 \mathrm{~kg}$ medicine ball with rough surface and circumference of $0.59 \mathrm{~m}$ (9). Preceding the tests, each participant executed several throws for warm-up. Each participant executed 3 throws with 2 minutes rest between attempts. The subjects were seated with their back against the wall holding the ball with both hands, resting it against the chest. Participants were asked to throw the medicine ball for the maximum possible distance, as far and fast as possible. Three technical valid attempts were used to calculate the average for analysis (intraclass correlation coefficient (ICC) values were always higher than 0.97). Throwing distance was measured using a measuring tape.

Vertical jump height (in centimeter) was obtained with the use of countermovement jump (9). For that purpose, a contact mat connected to an electronic power time (Ergojump, Globus, Italy) was used. Each subject started in the upright position with feet shoulder-width apart and squatted down until a 90 degrees angle of knees. Immediately after this moment, they jumped as high as possible, always with hands on the hips. Landing was made with both feet at the same time and with extended lower limbs. A 2-minute rest was accomplished between each of the 3 jumps. The average of 3 valid attempts was taken to analysis (ICC values were always higher than 0.95).
Swimming performance tests were executed after a standard warm-up (equal to the tethered swimming test) in a $25 \mathrm{~m}$ indoor swimming pool. A short distance time trial was chosen due to the influence of force application over these distances $(18,25)$. All subjects completed 2 maximal tests of $50 \mathrm{~m}$ in front crawl to access their best time (in seconds) in each test $(10,11$ ) (ICC values between 0.93 and 0.98$)$. A 15 minutes active recovery period between the 2 trials was respected. The starts were performed in the starting block. Time was measured by 2 experienced researchers with a chronometer (SEIKO S120-4030, Japan).

\section{Statistical Analyses}

Variables were expressed as means and standard deviations. After normality and homoscedasticity assumption were checked (Shapiro-Wilk and Levene tests, respectively), parametric tests were conducted. One-way ANOVA was performed to analyze possible differences over the groups at baseline. Repeated measures (within-subjects ANOVA) analysis of the variables according to the groups was performed. After this, a repeated measures factorial analysis (2-way ANOVA: moments $\times$ groups) was conducted. ANOVA repeated measures were followed by Bonferroni tests. The level of statistical significance was set at $p \leq 0.05$. The effect size was computed based on the partial eta-squared $\left(\eta_{p}^{2}\right)$ procedure, and values interpreted as: without effect if $0<$ $\eta_{p}^{2} \leq 0.04$; minimum if $0.04<\eta_{p}^{2} \leq 0.25$; moderate if $0.25<$ $\eta_{p}^{2} \leq 0.64$; and strong if $\eta_{p}^{2}>0.64$.

\section{Results}

A total of 21 participants ( 7 in GR1, 7 in GR2, and 7 in CG) were measured at baseline and postintervention. Outcomes were attained for all variables and there were no dropouts. At baseline, there were no significant differences between any of the analyzed variables (Table 1), thus, presenting acceptable homogeneity between groups.

Table 3 presents the results for the tethered swimming and dry-land tests, at the beginning of the experimental period (T1), after 6 weeks of the dry-land S\&C program (T2) and after 4 weeks of an adaptation period to strength gains (T3) for the 3 groups. Both mean force and mechanical impulse did not present a time or group effect, nor a time $\times$ group interaction. For the dry-land tests, a time effect was observed between T1 and T2 for the GR1 and GR2 in the vertical jump $(p<0.01)$, and for the GR2 in the ball throwing $(p<$ 0.01 ), with moderate to strong effect sizes. No group effect or time $\times$ group interaction was observed.

Table 4 presents the front crawl swimming performance, at the beginning of the experimental period (T1), after 6 weeks of the dry-land S\&C program (T2) and after 4 weeks of an adaptation period to strength gains (T3) for the 3 protocol groups. The 6 weeks of the dry-land S\&C program did not improve swimming performance for any group. However, the 4-week adaptation period allowed GR2 to significantly improve swimming performance $(p=0.03)$, with 
a moderate effect size. With regard to the group effect within the 3 moments, no differences between groups were identified. The time $\times$ group analyses showed that for performance in the $50 \mathrm{~m}$, differences were significant, with the GR2 presenting higher improvements than their counterparts $\left(F=4.156 ; p=0.007 ; \eta_{p}^{2}=0.316\right)$.

\section{Discussion}

The aim of this investigation was to examine the effects of a 10 -week training period of swim training alone, a 6-week dry-land $\mathrm{S} \& \mathrm{C}$ training program based on sets and repetitions according to current guidelines, plus 4 weeks of swim training alone or a 6-week dry-land $\mathrm{S} \& \mathrm{C}$ training program focused on explosiveness, plus 4 weeks of swim training alone, in age group swimmers. The main results showed that dry-land $\mathrm{S} \& \mathrm{C}$ training at these ages induces gains in dry-land measurements, but improvement in swimming performance only occurs after an adaptation period, thus confirming hypothesis 1 . By allowing an adaptation period of 4 weeks, an improvement in swimming performance was noted for the group that engaged in the dry-land $\mathrm{S} \& \mathrm{C}$ program with a focus on explosiveness, thus confirming hypothesis 2 .

Improvements in swimming performance have been associated with increases in power output $(5,24,29,32)$, which are elucidated by higher force application in the water (2). One of the available procedures to assess in-water propulsive forces and that can be used to evaluate force contribution for short-distance swimming performance is tethered swimming (19). Therefore, it was expected that dry-land strength gains would lead to higher levels of in-water force exertion (23). However, for these swimmers that did not occur. The increases in mean force and mechanical impulse were lower than the ones obtained with older swimmers (27), who, with $6 \%$ increase, also were not able to enhance their swimming performance. Stroke kinematics and propulsive efficiency can be a decisive factor to explain this bias, thus, further studies controlling stroke efficiency are mandatory to clear the relationship between strength gains and the ability to exert force in the water. Moreover, competitive level (9) and age may have influenced the transferability of dry-land strength training gains to in-water force production. It could be interesting to explore whether a similar bias would occur with more experienced and higher level swimmers. Still, after the 4 weeks of adaptation, a tendency to increase mean force and mechanical impulse was noticed, in both experimental groups. In fact, of those 14 swimmers, only 3 did not increase their mechanical impulse, suggesting that this period led to a cascade of events linking dry-land strength to aquatic performance.

For dry-land strength assessments, both experimental groups obtained significant improvements in jumping height, whereas the control group did not. This is in accordance with previous results (9), suggesting that a dry-land $\mathrm{S} \& \mathrm{C}$ program in age group swimmers could lead to higher levels of strength in the lower limbs. This may be of high importance for short distance events, as the swimming start is known to be a determinant factor for success (34). Furthermore, swimmers were able to maintain their jumping height after the dry-land $\mathrm{S} \& \mathrm{C}$ program cessation, confirming that 4 weeks were not enough for losing strength gains (35). For the upper limbs, only GR2 obtained significant improvements in the medicine ball throw. This group had a dryland S\&C program focused on explosiveness, which may have led to higher specificity transferable for swimming, as adolescent male swimmers obtain higher swimming velocities due to the high force exertion with their arm stroke (20). Even though literature about the detraining period in prepubescence is not extensive, it is suggested that strength and power training-induced gains tend to revert during detraining (7), mainly explained by neuromuscular forgetting (35). Available literature claims that a multidimensional $\mathrm{S} \& \mathrm{C}$ training in young athletes is crucial in several domains $(7,8)$. For instance, it can improve athletic performance and prevent sports related injuries. On the other hand, stronger young athletes will be able to succeed in the long-term demands of their sports careers (7).

Previous investigations stated that the risk of losing strength gains is not present until 6 weeks after the cessation of a strength training program (35). Furthermore, dry-land strength and power gains are maintained with a minimal stimulus contrarily to water strength and power gains, which require a more frequent and consistent stimulus, due to water-action specificity (35). In our investigation, swimmers were tested not only at the end of the dry-land S\&C program, but also 4 weeks afterwards. During this latter period, swimmers only performed their regular swimming training, aiming technical and propulsive adaptations to their new strength gains. Results showed that swimmers from GR2 had benefits from that period, improving swimming performance; before that, dry-land strength gains were not transferable to swimming performance, as stated by Garrido et al. (9). These outputs may suggest that this group followed a dry-land $\mathrm{S} \& \mathrm{C}$ training methodology more specific to sprint swimming events. Additionally, a period of overload decrement (strength training cessation) may induce a positive delay transformation to enhanced specific performance (36). Thus, swimming coaches should take into consideration both a suitable methodology for dry-land $\mathrm{S} \& \mathrm{C}$ prescription, and a proper time window to adapt swimmers to new force levels.

We believe that the main limitation of this study was the sample size. A sample size of 7 swimmers in each group does not assure an extensive generalizability, thus, further studies should engage more swimmers per group. Secondly, future investigations should try to extend experimental design during the season, attempting to evaluate longer term effects. This may provide clearer insights for training prescription.

Among several dry-land and in-water methodologies used by coaches and practitioners, dry-land $\mathrm{S} \& \mathrm{C}$ training programs are common in swimming, and positive results have 
been reported in previous investigations. To the best of our knowledge, this is the first investigation with age group swimmers that examined (a) 2 different approaches for dry-land $\mathrm{S} \& \mathrm{C}$ training and (b) an adaptation period to dryland strength gains, regarding swimming performance. Previous studies were conducted with older and more skilled swimmers than the ones who participated in this investigation. At these ages, swimmers do not have a specialization in a swimming technique, what may suggest that benefits of dry-land strength programs in swimming performance can be achieved at younger ages. Despite performing the same dry-land exercises, only GR2 obtained significant improvements in swimming performance. These results suggest that being able to perform the repetition rapidly had higher benefits for achieving higher swimming speed. It is known that swimming power is a critical factor to achieve swimming success $(2,21)$, particularly in short distances $(5,18,25,29)$. Nevertheless, several dry-land S\&C training programs followed a $1 \mathrm{RM}$, which is more related to maximum force than to power. This may constrain the specificity of the movement concerning the velocity and may jeopardize swimming performance enhancement (12). In fact, not giving so much importance to the velocity of the movement could have been the factor that constrained swimming performance enhancement in GR1. Furthermore, in-water muscular tension (3) could have been more replicated in GR2 exercises. Actually, power depends on the quick and large activation of muscle fibers and its synchronization. Thus, neural adaption happened as far as swimmers got stronger and body weight did not alter significantly-a process suggested to improve work economy (13). Additionally, it was shown that muscular recruitment was higher for maximal swimming speed than for low speed (22). This should reinforce the properness of using explosiveness in training sessions and evaluations.

\section{Practical Applications}

It is known that dry-land $\mathrm{S} \& \mathrm{C}$ programs are a common practice in swimming, independent of age or competitive level. First, dry-land $S \& C$ programs for age group swimmers with a small investment in materials and easy transportability are presented. Secondly, 6 weeks of complementary dry-land $\mathrm{S} \& \mathrm{C}$ training led to improvements in dry-land strength, which were beneficial for aquatic performance only after a 4-week adaptation period. That will lead to higher probabilities of being able to efficiently apply force in the water. Furthermore, it seems that additional benefits may occur if coaches plan the dry-land training focusing on explosiveness.

\section{ACKNOWLedGMents}

The authors thank all swimmers and coaches who participated in this research. This work was supported by University of Beira Interior and Santander Totta Bank (UBI/FCSH/Santander/2010), by the National Funds through FCT-Portuguese Foundation for Science and Technology (UID/DTP/04045/2013)-and the European
Fund for regional development (FEDER) allocated by European Union through the COMPETE 2020 Program (POCI01-0145-FEDER-00696.

\section{REFERENCES}

1. Aspenes, S, Kjendlie, PL, Hoff, J, and Helgerud, J. Combined strength and endurance training in competitive swimmers. J Sport Sci Med 8: 357-365, 2009.

2. Barbosa, TM, Bragada, JA, Reis, VM, Marinho, DA, Carvalho, C, and Silva, AJ. Energetics and biomechanics as determining factors of swimming performance: Updating the state of the art. J Sci Med Sports 13: 262-269, $2010 \mathrm{~b}$.

3. Barbosa, TM, Costa, M, and Marinho, DA. Proposal of a deterministic model to explain swimming performance. Int $J$ Swimming Kinetics 2: 1-54, 2013.

4. Barbosa, TM, Costa, M, Marinho, DA, Coelho, J, Moreira, M, and Silva, AJ. Modeling the links between young swimmer's performance: Energetic and biomechanical profiles. Pediatr Exerc Sci 22: 379-391, 2010a

5. Barbosa, TM, Morais, JE, Marques, MC, Costa, MJ, and Marinho, DA. The power output and sprinting performance of young swimmers. J Strength Cond Res 29: 440-450, 2015.

6. Bencke, J, Damsgaard, R, Saekmose, A, Jorgensen, P, Jorgensen, K, and Klausen, K. Anaerobic power and muscle strength characteristics of 11 years old elite and non-elite boys and girls from gymnastics, team handball, tennis and swimming. Scand J Med Sci Sport 12: 171-178, 2002.

7. Faigenbaum, AD, Kraemer, WJ, Blimkie, CJR, Jeffreys, I, Micheli, LJ, Nitka, M, and Rowland, TW. Youth resistance Training: Updated position statement paper from the National Strength and Conditioning Association. J Strength Cond Res 23: S60-S79, 2009.

8. Faigenbaum, AD, Lloyd, RS, MacDonald, J, and Myer, GD. Citius, Altius, Fortius: Beneficial effects of resistance training for young athletes. Br J Sports Med 0: 1-7, 2015.

9. Garrido, N, Marinho, DA, Reis, VM, Van Den Tillaar, R, Costa, AM Silva, AJ, and Marques, MC. Does combined dry land strength and aerobic training inhibit performance of young competitive swimmers? J Sport Sci Med 9: 300-310, 2010.

10. Girold, S, Jalab, C, Bernard, O, Carette, P, Kemoun, G, and Dugué, B. Dry-land strength training vs. electrical stimulation in sprint swimming performance. J Strength Cond Res 26: 497-505, 2012.

11. Girold, S, Maurin, D, Dugue, B, Chatard, JC, and Millet, G. Effects of dry-land vs. resisted- and assisted-sprint exercises on swimming sprint performances. J Strength Cond Res 21: 599-605, 2007.

12. González-Badillo, JJ and Sánchez-Medina, L. Movement velocity as a measure of loading intensity in resistance training. Int J Sports Med 31: 347-352, 2010.

13. Hoff, J, Gran, A, and Helgerud, J. Maximal strength training improves aerobic endurance performance. Scand J Sports Sci 11: 288-295, 2002.

14. Keskinen, KL, Tilli, LJ, and Komi, PV. Maximum velocity swimming: Interrelationships of stroking characteristics, force production and anthropometric variables. Scand J Sports Sci 11: 87-92, 1989.

15. Leveritt, M, Abernethy, P, Barry, BK, and Logan, PA. Concurrent strength and endurance training. A review. Sports Med 28: 413-427, 2000 .

16. Lucero, B. Strength Training for Faster Swimming. Aachen, Germany: Meyer \& Meyer Sport, 2011

17. Maglischo, EW. Swimming Fastest. Champaign, IL: Human Kinetics, 2003.

18. Morouço, P, Keskinen, KL, Vilas-Boas, JP, and Fernandes, RJ. Relationship between tethered forces and the four swimming techniques performance. J Appl Biomech 27: 161-169, 2011a.

19. Morouço, P, Marinho, DA, Keskinen, K, Badillo, J, and Marques, MC. Tethered swimming can be used to evaluate force contribution for short-distance swimming performance. J Strength Cond Res 28: 3093-3099, 2014 
20. Morouç, PG, Marinho, DA, Izquierdo, M, Neiva, HP, and Marques, MC. Relative contribution of arms and legs in 30s fully tethered front crawl swimming. Bio Med Res Int, 2015: 563206. doi: $10.1155 / 2015 / 563206,2015$

21. Newton, RU, Jones, J, Kraemer, WJ, and Wardle, H. Strength and power training of Australian Olympic Swimmers. Strength Cond J24: $7-15,2002$.

22. Rouard, AH, Quezel, G, and Billat, RP. Effects of speed on emg and kinematic parameters in freestyle. In: Biomechanics and Medicine in Swimming VI. Maclaren, D, Reilly, T and Lees, A, eds. London, United Kingdom: E \& FN Spon Press, 1992. pp. 93-97.

23. Sadowski, J, Mastalerz, A, Gromisz, W, and Niźnikowski, T. Effectiveness of the power dry-land training programs in youth swimmers. J Hum Kinet 32: 77-86, 2012.

24. Sharp, RL, Troup, JP, and Costill, DL. Relationship between power and sprint freestyle swimming. Med Sci Sports Exerc 14: 53 56, 1982.

25. Stager, JM and Coyle, MA. Energy systems. In: Swimming-Handbook of Sports Medicine and Science. Stager, J and Tanner, D, eds. Boston, MA: Blackwell Science, 2005. pp: 1-19.

26. Strass, D. Effects of maximal strength training on sprint performance of competitive swimmers. In: Swimming Science $V$. Ungerechts, BE, Wilke, K, and Reischle, K, eds. London, United Kingdom: Spon Press, 1988. pp: $149-156$.

27. Tanaka, H, Costill, DL, Thomas, R, Fink, WJ, and Widrick, JJ. Dry-land resistance training for competitive swimming. Med Sci Sports Exerc 25: 952-959, 1993.
28. Tolfrey, K. Responses to training. In: Paediatric Exercise Science: Advances in Sport and Exercise Ecience Series. ed. Edinburgh, Scotland: Armstrong N. Churchill Livingstone, 2007. pp: 213-234.

29. Toussaint, HM. Strength power and technique of swimming performance: Science meets practice. In: Schwimmen Lernen und Optimieren. Leopold, W, ed. Beucha, Deutschland: SchwimmtrainerVereinigung V, 2007. pp. 43-54.

30. Toussaint, HM, Beelen, A, Rodenburg, A, Sargeant, AJ, de Groot, G, Hollander, AP, and van Ingen Schenau, GJ. Propelling efficiency of front crawl swimming. J Appl Physiol (1985) 65: 2506-2512, 1988.

31. Toussaint, HM and Hollander, AP. Energetics of competitive swimming: Implications for training programs. Sports Med 18 384-405, 1994

32. Toussaint, HM and Vervoorn, K. Effects of specific high resistance training in the water on competitive swimmers. Int J Sport Med 11 228-233, 1990.

33. Trappe, $S$ and Pearson, DR. Effects of weight assisted dry-land strength training on swimming performance. J Strength Cond Res 8: 209-213, 1994

34. Vantorre, J, Chollet, D, and Seifert, L. Biomechanical analysis of the swim-start: A review. J Sport Sci Med 13: 223-231, 2014.

35. Wilmore, J and Costill, D. Physiological adaptations to physical training. In: Training for Sport and Activity Chapter 11. Dubuque, IA: Wm. C. Brown, 1988.

36. Zatsiorsky, VM. Science and Practice of Strength Training. Champaign, IL: Human Kinetics, 1995. 